\title{
Influence of Biopolymers on the Mechanical Behavior of Earth-Based Building Materials
}

Julia Tourtelot ${ }^{1,2}$, Ann Bourgès ${ }^{3}$, Emmanuel Keita ${ }^{1,}$ *

1. Navier Lab, University Gustave Eiffel, ENPC, CNRS, Champs-sur-Marne, France; E-Mails: julia.tourtelot@univ-eiffel.fr; Emmanuel.keita@univ-eiffel.fr

2. Laboratoire de Recherche des Monuments Historiques, Champs-sur-Marne, France

3. C2RMF, Centre de Recherche et de Restauration des Musées de France, France-Institut de Recherche Chimie Paris, PSL Research University, Chimie ParisTech-CNRS, Paris, France; E-Mail: ann.bourges@culture.gouv.fr

* Correspondence: Emmanuel Keita; E-Mail: Emmanuel.keita@univ-eiffel.fr

Academic Editor: Jorge de Brito

Special Issue: Wastes, Residues and Byproducts for the Production of Construction Materials

Recent Progress in Materials

2021, volume 3, issue 3

doi:10.21926/rpm.2103031
Received: March 09, 2021

Accepted: July 08, 2021

Published: July 26, 2021

\begin{abstract}
Currently, the largest among the earth excavation sites in Europe are located in the Paris region. The soils excavated from these sites are often considered waste and are not valorized. With an increasing focus on sustainable development, the demand for low-carbon building materials is rising. Although construction using raw earth is a vernacular technique, the diversity in the behavior of the raw earth building materials warrants better control of their mechanical properties. The construction techniques differ depending on the location of the site, the composition of the earth, and the stabilizers used. Plant-based fibers and compounds extracted from plants are commonly used for reinforcing raw earth. Since such byproduct solutions have been developed worldwide, they differ significantly, and it becomes difficult to set a benchmark. The majority of the reported studies have directly used organic waste, rendering it difficult to characterize the material and extend the obtained results to other contexts. In order to reduce these variabilities, it becomes important to study the
\end{abstract}


reinforcement of earth-based building materials with biopolymers that constitute the active molecules of the bio-based solutions. In the present study, different biopolymers derived from various vernacular techniques were utilized to increase the compressive strength of the construction soil collected from the Paris region. It was revealed that cellulose fibers and wheat starch increased the compressive strength of the earth from 3.5 MPa to 5.5 MPa and 4.5 $\mathrm{MPa}$, respectively. In addition, the interactions of these biopolymers with clay were analyzed. The biopolymers identified as suitable for use in construction materials in the present study are widely available as wastes from paper, agricultural, or agro-food industries. These identified biopolymers would contribute to the development and standardization of construction using earth-based building materials.

\section{Keywords}

Earth-based building materials; biopolymers; mechanical behavior; compressive strength

\section{Introduction}

The increasing focus on sustainable development has led to high demand for low-carbon building materials. A simple solution to this is to reduce the quantity of cement in the building materials and replace it partially with industrial co-products or other binding materials such as clay [1-4]. The Paris region currently has the largest earth excavation sites in Europe [11], and the soils excavated from these sites are considered waste and are not valorized. These soils could be used in construction as components of building materials. Construction using raw earth is a vernacular technique. Different methods are used depending on the location, the composition of the earth, and the stabilizers available. For instance, the building material could be compressed, filled with fibers, or poured [510].

The diversity in the composition and behavior of raw earth warrants control of its mechanical properties $[12,13]$. This objective could be achieved using two approaches. The first approach is earth stabilization using an inorganic material, such as cement or lime. However, this stabilization approach modifies the building material and might consequently increase its carbon footprint [2, 14-18]. The second approach is to stabilize the earth organically using various organic additives from wastes or byproducts, depending on the availability at/close to the construction. Plant-based fibers, animal fibers, and compounds extracted from plants are commonly reported for use in raw earth reinforcement $[4,19-25]$.

Various low-carbon solutions have been developed worldwide, which results in significant differences among the solutions, rendering it difficult to set a benchmark. The majority of the reported studies have directly used organic waste, due to which it becomes difficult to characterize the building material and extend the results to other contexts. In order to reduce such variabilities, it becomes important to study the reinforcement of earth-based building materials with biopolymers that serve as the active molecules of these bio-based solutions. However, it should be ensured that these biopolymers do not influence the environmental footprint (LCA) of the material. The biopolymers from organic sources, such as agricultural byproducts, are best suited for the 
purpose. Such biopolymers would contribute immensely to the development and standardization of the earth-based construction industry.

In this context, the present study aimed to analyze the influence of different biopolymers derived from vernacular techniques on the compressive strength of the construction soil collected from the Paris region. The bio-based additives from known solutions were identified, and the influence of the extracted biopolymers on the mechanical behavior (compressive strength, critical strain, and elastic modulus) of the construction soil was measured quantitatively. Furthermore, the interactions of these biopolymers with clay were also analyzed.

\section{Selection of Biopolymers}

In the present study, biopolymers are defined as the high-molecular-weight molecules extracted from bio-based additives. Relevant biopolymers were identified based on the referencing of traditional recipes reported by the PaTerre+ project group, funded by the French Ministry of Culture and Communication [24, 26], which documents 29 traditional recipes used across the world for the stabilization of raw earth using biopolymers. All these recipes involve the use of local organic resources, which are mostly waste, byproducts, or residues from agriculture and available locally around or close to the construction site $[19,21-23,27]$. These biopolymers could be from plants, plant byproducts, algae, or animal sources. Biopolymers are classified into four major categories polysaccharides, lipids, proteins, and complex molecules. According to reports, these biopolymers appear to improve the properties of raw earth.

With the objective of developing sustainable constructions using raw earth, in the present study, biopolymers rather than complete plants were used for improving the mechanical properties of the construction earth $[1,2]$. In total, ten biopolymers, covering all four major categories, were selected, including six polysaccharides, one lipid, one protein, and two complex molecules.

Polysaccharides are the most frequently occurring biopolymers in nature. These are composed of sugar units. Cellulose is a ubiquitous polysaccharide, composed of $\beta(1,4)$ linked D-glucose units linked in a linear chain. At the molecular level, cellulose comprises helix and fiber arrangements. These two levels of arrangement are stabilized by the hydrogen bonds formed between the numerous $\mathrm{OH}$ groups present in the structure. In plants, these fibers are held together by lignin. Polysaccharides exist in varying degrees of purity, crystallinity, and dimensions depending on their botanical source and the mechanical and chemical treatments employed for their extraction [2830].

Cellulose fibers constitute the main component of wood. In order to improve the mechanical and chemical resistance of wood, cellulose bonds with hemicellulose and lignin mainly. Hemicellulose is a branched polymer comprising xylose sugar and is difficult to separate from other wood components. The average lignin content in wood is $20 \%$. In the present study, cellulose fibers subjected to alkali treatment for lignin removal were selected and were designated as "alphacellulose" [31]. Moreover, lignin alone was also used in the construction earth used in the experiments. Lignin is an amorphous and hydrophobic biopolymer [32, 33]. Lignin is not a polysaccharide and rather a complex molecule that is highly branched. The major units in lignin are coniferyl alcohol, sinapyl alcohol, and paracoumaryl alcohol.

One of the purest forms of cellulose fibers ( $99 \%$ purity) is present in cotton, and it does not contain lignin. In the present study, two forms of cellulose were selected. One form had been 
subjected to a few processing steps and was designated as "cotton cellulose". The other one had been treated to preserve only the crystalline fraction of the fibers and was designated as the "microcrystalline cellulose" or " $\mu$-cellulose" [34, 35].

Besides lignin and cellulose, pectin also has a significant influence on the mechanical properties of plants, and this influence varies with the plant species [32]. Pectin is a polysaccharide present in the plant cell walls surrounding the cellulose fibers. Pectin is a block biopolymer, i.e., it comprises alternating linear and branched blocks. The sugar units in the pectin structure are mainly galactose. Among the plant sources of pectin, fruits contain the highest pectin content. Therefore, apple pectin was selected for use in the present study and is, hereafter, referred to as "pectin" [36].

Traditional recipes for earth-based construction materials often include starch, which is also present in certain agricultural products. Similar to cellulose, starch is also a polysaccharide, which comprises glucose units linked with $\alpha(1,4)$ bonds. Starch does not form fibers and is present mainly in cereals and tubers. Starch serves as an energy source for plants, animals, and humans. In plants, starch is present in the form of granules of different shapes and sizes depending on the botanical source. These granules have an onion-like structure internally, with each layer comprising two constituent polysaccharides - amylose and amylopectin. Amylose is a long linear biopolymer, and amylopectin is a branched biopolymer. In the present study, wheat starch was selected as it has been used in traditional recipes based on flour glue. Traditionally, the granules crack in boiling water, following, which the polymeric chains gel as the temperature decreases [37-41].

Finally, among the polysaccharides, sodium alginate produced by brown algae was selected and designated as "Na-alginate" [42]. In Japan, sodium alginate is mostly used for producing smooth coatings. Sodium alginate is a linear block copolymer comprising blocks of mannuronate units linked with blocks of guluronate units. Sodium alginate is soluble in water and gels when it comes in contact with chelating metallic ions, such as calcium and magnesium ions. These two metallic ions are already present in the earth and, therefore, the addition of sodium alginate to the construction earth would result in the formation of a linking gel inside the earth mix.

Furthermore, bovine casein was selected as the protein and is designated as "casein" hereafter. Bovine casein is isolated from milk and is used as a coating agent for earthen surfaces. It is a globular phosphoprotein that is insoluble in water [43]. In traditional recipes, the milk pH is decreased using ammonium or by adding ions [44, 45]. This causes the casein protein to form a gel, which is then used as a glue or a coating agent for earthen surfaces. In the present study, the aqueous solution of casein was used with sodium hexametaphosphate (NaHMP) for promoting gel formation [46-48].

In the lipid category, linseed oil was selected. Linseed oil is hydrophobic in nature and, therefore, known to protect the earth against water. Therefore, it is generally used as a coating agent for earthen surfaces [49]. Moreover, linseed oil polymerizes under the influence of heat and the sun. These properties enable this novel biopolymer to form a protective 3D structure inside the construction earth.

Finally, the last biopolymer selected was tannic acid from the category of complex molecules. Similar to lignin, tannins are also present in wood. Both tannins and lignin are polyphenols. The structure of tannic acid varies with its botanical source and the different growing conditions of the plant. After solubilization in water, tannic acid is used as the coating agent for earthen surfaces. Tannic acid forms complexes with metallic ions, thereby creating negative charges in the function of $\mathrm{pH}$ or dispersing clays. Tannins modify the behavior of the earthen material as the arrangement of earth particles is a function of the earth's composition and the nature of the tannin [50-52]. 
Finally, the ten biopolymers selected were mixed in the earth mortar to produce adobe-like bricks. The proportion of each biopolymer was adjusted according to the traditional recipes and the literature. Vegetal fibers are used extensively and in huge quantities in earth-based building materials. Therefore, in the present study also, cellulose and lignin were added to the mortar mixes, each at a concentration of $10 \%$ of the construction earth. On the contrary, the other biopolymers are usually added in smaller quantities as they may form gels or due to their higher reactivity. Therefore, in the present study, casein was used at $5 \%$ of the mass of the earth, while the other biopolymers in the traditional recipes (pectin, wheat starch, sodium alginate, linseed oil, and tannic acid) were added at $1 \%$ each. All the mortar proportions are detailed in section 3.2.

\section{Materials and Methods}

\subsection{Materials}

\subsubsection{Inorganic Materials}

In the present study, earth collected from the "Briqueterie deWulf" in the Paris region in France was used after mixing with sand to limit shrinkage and avoid cracks during drying.

This earth contained approximately $9 \%$ clay, which is defined as the soil containing particles of size under $2 \mu \mathrm{m}$. The grain size distribution of the earth used is plotted in Figure 1. The XRD diffractogram revealed that the clays present in the earth were smectites, vermiculites, illite, and kaolinite (Figure 2 and Table 1). The main clay was illite, accounting for $7 \%$ of the earth. The Atterberg limits and the cation exchange capacity (CEC) of the pure samples of these clays are presented in Table 2. The CEC, in milliequivalents per $100 \mathrm{~g}$ of dry solid, was measured through exchange with cobalthexamine, the liquid limit was determined using the conventional method proposed by Casagrande, and the plastic limit was determined by rolling out a thread [53].

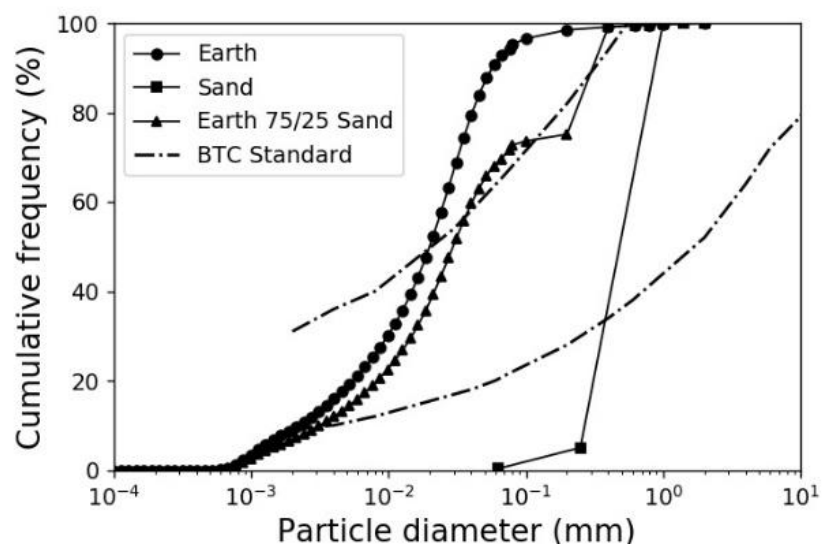

Figure 1 Cumulative particle size distribution of the earth and the sand, the 75/25 earth sand sample, and the BTC standard [54]. 


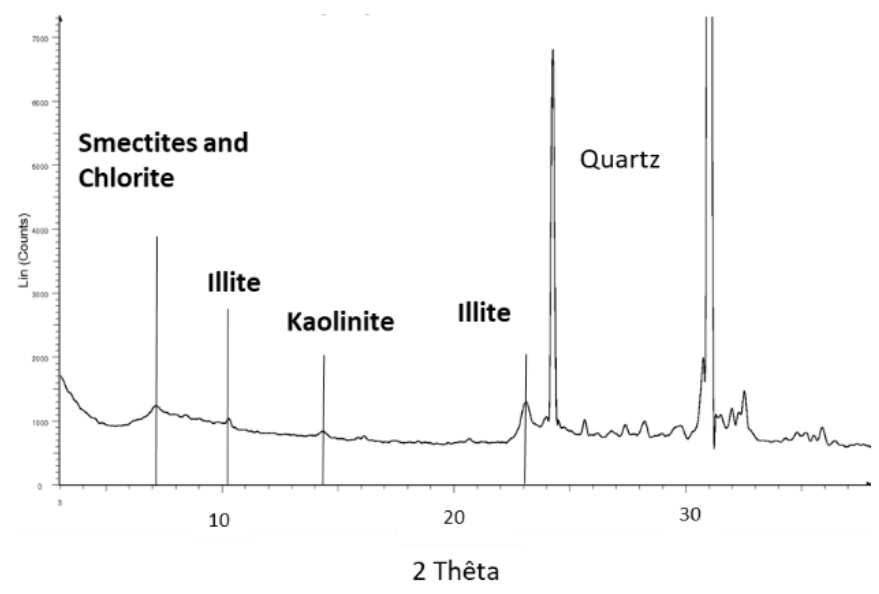

Figure 2 XRD spectrograph of the earth with the identified constituent minerals.

Table 1 Fractions of different clays identified in the earth.

\begin{tabular}{lllll}
\hline Clays & Smectites & Illite & Chlorite & Kaolinite \\
\hline Fraction (\%) & Traces & $7.0 \pm 0.7$ & $1.0 \pm 0.7$ & $0.5 \pm 0.5$ \\
\hline
\end{tabular}

Table 2 Properties of the earth.

\begin{tabular}{lll}
\hline $\begin{array}{l}\text { CEC } \\
\text { (meq/100 } \mathbf{~ g ) ~}\end{array}$ & $\begin{array}{l}\text { Plastic limit } \\
\text { water content (\%) }\end{array}$ & $\begin{array}{l}\text { Liquid limit } \\
\text { water content (\%) }\end{array}$ \\
\hline $17.9 \pm 0.5$ & 21.9 & 35.1 \\
\hline
\end{tabular}

The sand used was from the "Sablières Palvadeau" in France. It is a naturally rounded sand, with particles of size range $0.315-1 \mathrm{~mm}$ (Figure 1 ).

\subsubsection{Biopolymers}

Ten different biopolymers were used in the present study. Nine of these biopolymers, cotton cellulose, $\alpha$-cellulose, microcrystalline cellulose, lignin, casein, pectin, wheat starch, tannic acid, and sodium alginate, were purchased from Sigma-Aldrich. The size distribution of these biopolymers was measured in distilled water through either diffusion light scattering or laser granulometry; The median sizes are reported in Table 3. Since there were two biopolymers for wheat starch, two particle sizes are reported for it. Prior to conducting measurements, wheat starch was heated at $90{ }^{\circ} \mathrm{C}$ in distilled water for a few minutes. Casein was also heated at $60^{\circ} \mathrm{C}$ in an $8 \%$ aqueous solution of NaHMP. The biopolymer linseed oil, extracted using cold pressing, was purchased from a shop selling organic products. The viscosity of this linseed oil was $43 \mathrm{mPa}$.s.

Table 3 Sizes of different biopolymers in aqueous solution.

\begin{tabular}{lclc}
\hline Biopolymers & Size $(\mathrm{nm})$ & Biopolymers & Size $(\mathbf{n m})$ \\
\hline Cotton cellulose & $20 \cdot 10^{3}$ & Pectin & 350 \\
$\alpha$-cellulose & $90 \cdot 10^{3}$ & Wheat starch & $7.4 \& 35 \cdot 10^{3}$
\end{tabular}




\begin{tabular}{lcll}
$\mu$ cellulose & $30 \cdot 10^{3}$ & Tannic acid & 1 \\
Lignin & $10 \cdot 10^{3}$ & Sodium alginate & 150 \\
Casein & $100 \cdot 10^{3}$ & & \\
\hline
\end{tabular}

\subsection{Production of Bricks}

\subsubsection{Preparation of Biopolymers}

The literature recommends performing certain preparation steps prior to using biopolymers in earth-based construction. The celluloses, lignin, tannic acid, sodium alginate, and linseed oil were used as received, while the other biopolymers were transformed prior to usage.

Pectin forms a gel when it contacts water. Therefore, for pectin, the preparatory step included simple mechanical agitation in distilled water at the concentration of $2.5 \%$ by weight. The gel formed as a result was then used as the mixing water for preparing the mortars.

The molecules constituting wheat starch and casein require being released by heating prior to use in earth-based mortars. Therefore, wheat starch was heated at $90{ }^{\circ} \mathrm{C}$ for a few minutes in distilled water at a concentration of $5.8 \%$. Casein was also heated at $60^{\circ} \mathrm{C}$ at a concentration of $8.9 \%$ in a $0.8 \%$ aqueous solution of NaHMP. As the mixtures cooled down, gels were formed. These gels were then used as mixing waters for preparing mortars at room temperature.

\subsubsection{Production of Samples}

Mix Design. The present study aimed to investigate the influence of different vernacular biopolymers on the compressive properties of construction earth. In order to achieve this objective, a reference mortar mix was designed, which had a sand/earth mass ratio of 25/75 for limiting crack formation during drying. The particle size distribution of the sand/earth mix was plotted and is depicted in Figure 1 along with the plot for the BTC Standard [54]. Moreover, a water/materials ratio of $20.5 \%$ by mass was selected. Biopolymers were added to the reference mix in different proportions, referring to the values reported in the literature [24, 55-58]. Accordingly, the celluloses and lignin were used at $10 \%$ by mass [of the construction earth], casein was used at $5 \%$, while the other biopolymers (linseed oil, tannic acid, pectin, wheat starch, and sodium alginate) were used at 1\%. Finally, a total of eleven mixes were prepared: one was the reference mix with the earth, the sand, and the distilled water, while the other ten were corresponding to each biopolymer.

Mortar Mixes. All eleven mixes were prepared by following the same steps. First, the- earth and the sand- were mixed in a mixing bowl for 30 s using a spatula. Next, the -distilled water was-poured into the powder mix, followed by stirring in a planetary mixer for one minute at a constant speed of $67 \mathrm{rpm}$. The mixing was terminated after a minute, and the walls of the mixing bowl were scrapped. Subsequently, another round of mixing was performed at a constant speed of $125 \mathrm{rpm}$ for $30 \mathrm{~s}$. Afterward, the mixtures were allowed to rest for a minimum of $48 \mathrm{~h}$ in hermetical beakers. Prior to testing, the prepared mixes were homogenized in the planetary mixer at $67 \mathrm{rpm}$ for $30 \mathrm{~s}$.

Since the biopolymers exist in different forms, each was added at a different step in the process. The celluloses, lignin, tannic acid, and sodium alginate were poured into the bowl at the powdermixing step, while the pectin gel, wheat starch gel, and casein gel were poured into the mixing bowl at the liquid-mixing step. Finally, the linseed oil was added after the $30 \mathrm{~s}$ of mixing of the total mix 
(earth, sand, and water) at $67 \mathrm{rpm}$ to prevent aggregation of particles and enhance the uniform distribution of the biopolymer.

Molding and Drying. The mixes were molded inside cubic molds with a diameter of $5 \mathrm{~cm}$. Three cubic bricks were produced for each mix containing a biopolymer. Seven bricks were produced for the reference mix. The bricks were prepared by molding in two successive layers, each layer shocked by ten impacts using a shocking table to reproduce a handcrafted adobe production. The bricks were dried inside the molds in a room with controlled conditions of $20^{\circ} \mathrm{C}$ temperature and $60 \%$ relative humidity $(\mathrm{RH})$ until they could be unmolded (approximately 3 to 12 days). After unmolding, the bricks were placed in an oven at $30{ }^{\circ} \mathrm{C}$ and $20 \% \mathrm{RH}$ until a constant mass was achieved (approximately one week). The dry density of each brick was calculated using the following equation:

$$
\rho_{\text {dry }}=m / V,
$$

where, $\rho_{d r y}$ denotes the dry density, $\mathrm{m}$ denotes the mass, and $\mathrm{V}$ denotes the volume. The dry density of the reference brick was $1.87 \mathrm{~g} / \mathrm{cm}^{3}$.

\subsection{Compressive Test}

In the present study, the mechanical behavior was evaluated using only the compressive test. The test was performed using a Shimadzu AUTOGRAPH AGS-X press equipped with a $300 \mathrm{kN}$ force sensor. The surfaces of the dried bricks were flattened using a wood file, and bricks with horizontal and parallel surfaces were obtained. The bricks were compressed at a rate of $1 \mathrm{~mm} / \mathrm{min}$ [53]. Each test was photographed using a NIKON D300 camera at a rate of one image per second.

The stress is described by the equation below:

$$
\sigma=F / A
$$

where $\sigma$ denotes the stress, $F$ represents the force, and A represents the horizontal surface. The compressive strength was considered the maximal stress.

The critical strain was calculated based on the first and last photographs of the fracturing record. Using the ImageJ software, the number of pixels on a median line corresponding to the brick's height was measured for each of the two photos. The critical strain value was calculated using the following expression:

$$
\varepsilon(\%)=\Delta l / l_{0} * 100
$$

where $\varepsilon$ denotes the critical strain, $\Delta l$ represents the difference between the initial and the final height of the brick, and $\mathrm{l}_{0}$ denotes the initial height of the brick.

Elastic modulus was considered the linear part of the slope of stress as a function of the strain measured from the press experiment. The linear part between $30 \%$ and $60 \%$ of the maximal stress was considered.

All the result values reported are the means of the values obtained in each compressive test, while the error bars correspond to the $90 \%$ confidence interval. Since only two bricks prepared from the sodium alginate mix were tested, the two results obtained are presented in each figure. 


\section{Results}

The present study aimed to investigate the effect of biopolymers on the mechanical properties of earth-based building materials from vernacular methods. In order to achieve this objective, ten biopolymers were evaluated by mixing them with the construction earth collected from the Paris region. Since all the materials used are natural, particularly the construction earth, there existed an inherent variability due to their origin, which is reflected in the confidence intervals.

The mechanical properties of the building materials were evaluated using a uniaxial compression test. The results of the compressive test revealed that the stress decreased smoothly after reaching its maximum value, which confirmed that the earthen materials' failure was ductile (Figure 3). Certain additions, such as linseed oil, extended the high-stress plateau to an almost infinite plateau. Moreover, biopolymers could also change the elastic modulus of the materials at a small strain value. For instance, cellulose and linseed oil increased the strain of the material by $1 \%$ prior to the break, implying that these biopolymers tend to decrease the elastic modulus. Furthermore, certain biopolymers could maintain the properties of the earth prior to breaking while increasing the maximum strength; for example, wheat starch increased the breaking strength by $1 \mathrm{MPa}$.

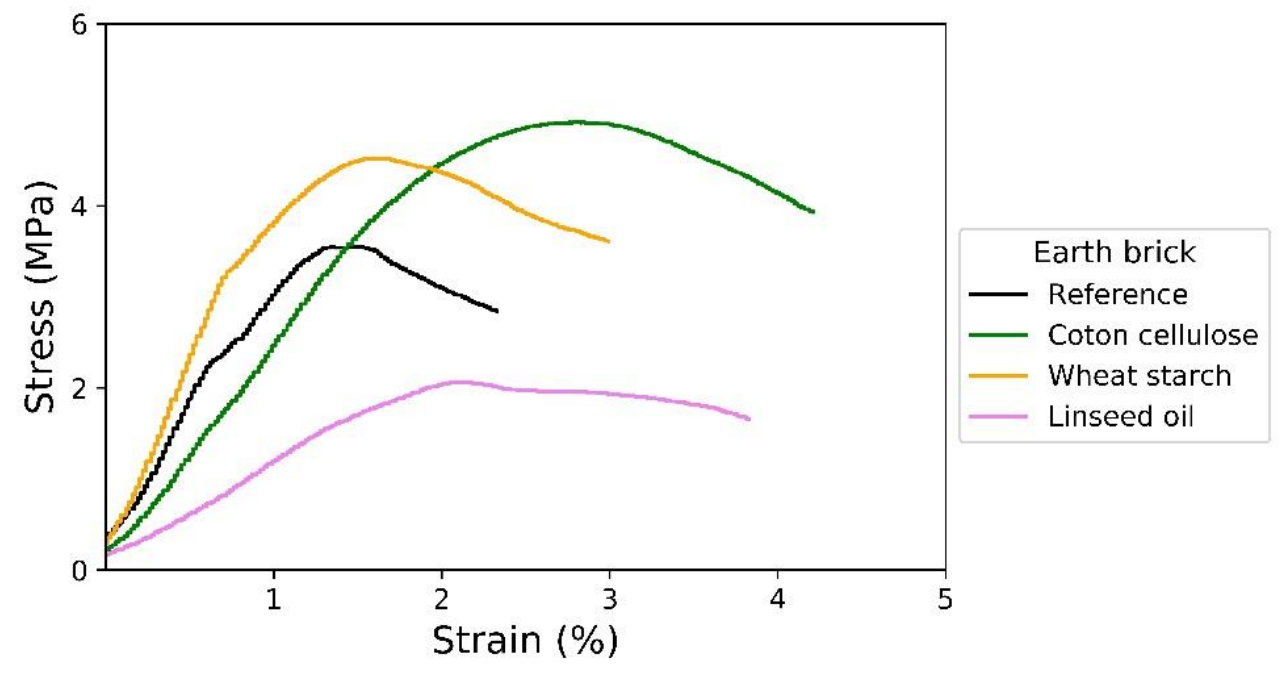

Figure 3 Stress plotted as a function of strain for selected samples.

The first property of interest was the critical strain of the bricks. Figure 4 depicts the maximum strain as a function of sample composition. In most cases, the addition of the biopolymer did not significantly modify the strain of the material, and the strain value was maintained at approximately $2.5 \%$. Nevertheless, there were variations in the confidence intervals. Most biopolymers increased the values of these standard deviations; for example, the value was increased up to $2 \%$ for alphacellulose, cellulose, and linseed oil, compared to the $0.5 \%$ value for the reference. On the contrary, lignin and casein decreased the confidence interval value by $0.4 \%$ and $0.1 \%$, respectively. The alphacellulose biopolymer exhibited a huge [and significant] increase of up to $5.5 \%$ in the strain value. 


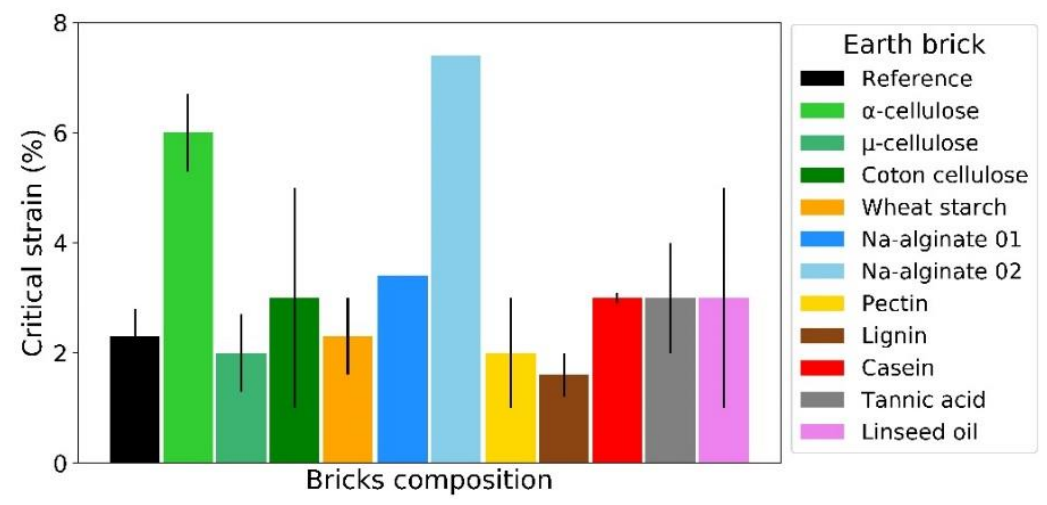

Figure 4 Critical strain as a function of biopolymer addition for all samples.

The main mechanical property evaluated was compressive strength. Since the value of comprehensive strength varies upon the application of consolidation techniques, this parameter is generally compared based on the dry density value of the material $[13,58]$. Figure 5 presents the comparison of these parameters for all the bricks. The dry densities ranged from 1.5 to $1.9 \mathrm{~g} / \mathrm{cm}^{3}$, with the reference value of $1.87 \mathrm{~g} / \mathrm{cm}^{3}$. Most biopolymers led to a decrease in the dry density of the brick, except for wheat starch, cellulose, and pectin, which maintained the dry density value close to the reference value. Lignin led to a strong decrease in the dry density value to $1.5 \mathrm{~g} / \mathrm{cm}^{3}$ while maintaining the compressive strength of the brick. It is noteworthy that tannic acid, linseed oil, and casein led to a decrease in the dry density and the fracture strength of the material. Therefore, it could be inferred that in the present study, the compressive strength of the material did not depend on the variation in the dry density of the material.

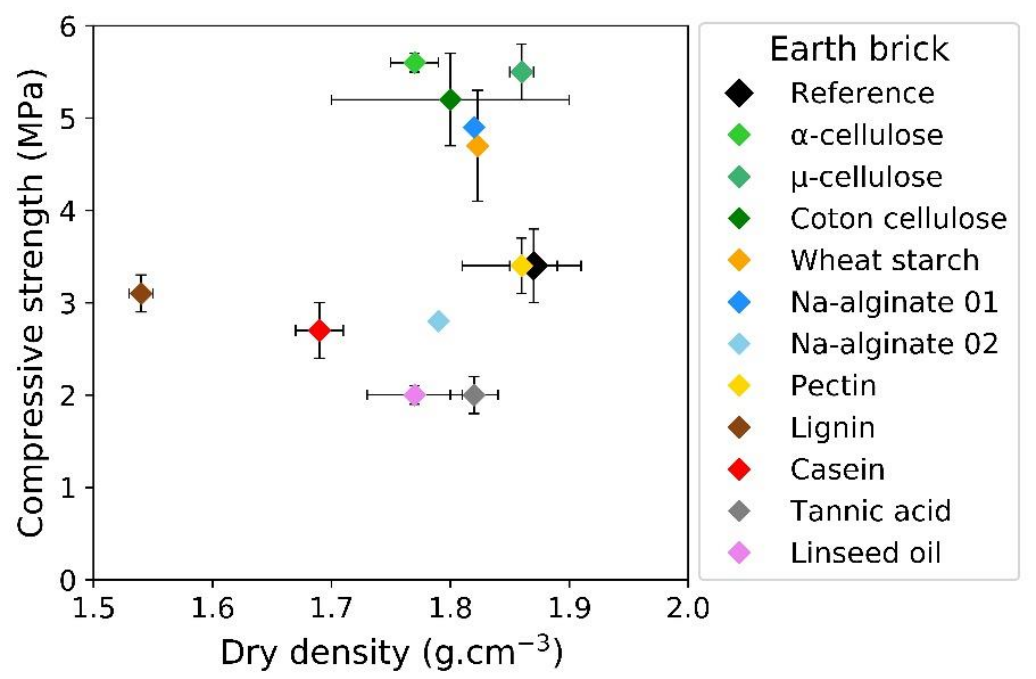

Figure 5 Compressive strength as a function of dry density for all samples.

The biopolymers evaluated in the present study could be classified as follows: the ones that decreased the compressive strength, the ones that maintained the comprehensive strength, and the ones that increased the comprehensive strength. Tannic acid, linseed oil, and casein decreased the compressive strength of the material by up to $1 \mathrm{MPa}$. Sodium alginate, pectin, and lignin exerted little or no effect on the compressive strength, maintaining it at approximately 3.5 MPa. Finally, the 
celluloses and wheat starch increased the compressive strength to $5.5 \mathrm{MPa}$ and $4.5 \mathrm{MPa}$, respectively.

The same categories were revealed when elastic modulus values were compared (Figure 6). While tannic acid, linseed oil, and casein decreased the elastic modulus to $100 \mathrm{MPa}$, the celluloses and wheat starch increased it to $400 \mathrm{MPa}$. Sodium alginate, pectin, and lignin maintained the elastic modulus at $200 \mathrm{MPa}$.

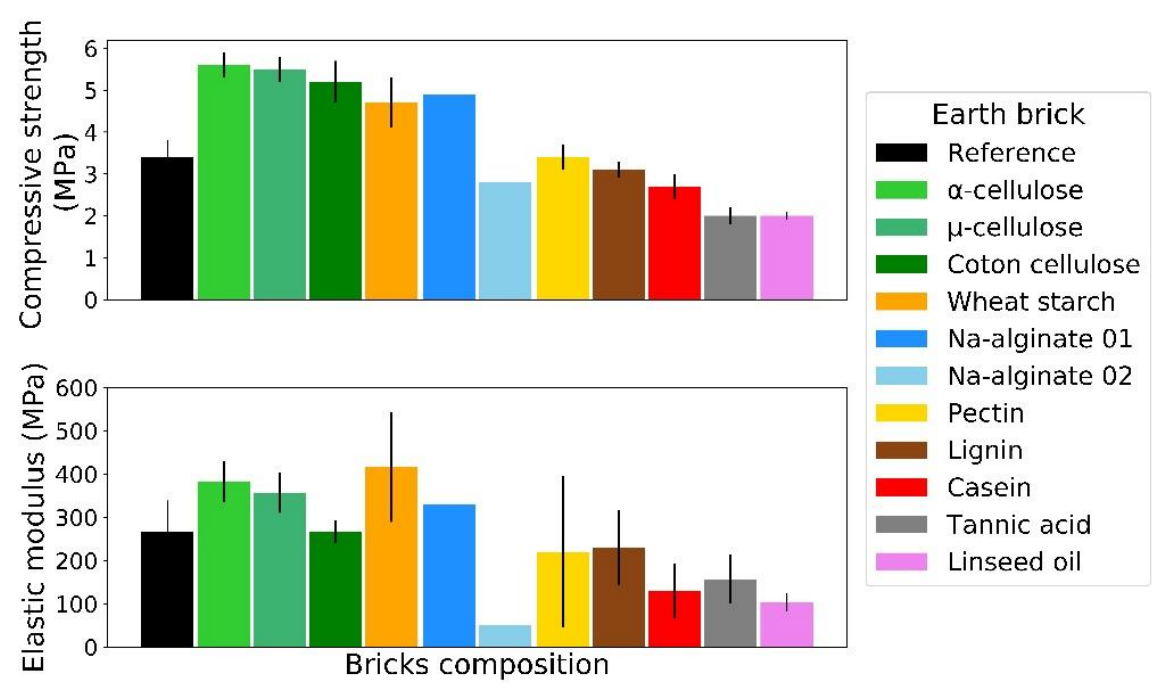

Figure 6 Compressive strength and elastic modulus as functions of biopolymer addition for all samples.

In summary, tannic acid, linseed oil, and casein weakened the analyzed earthen material while increasing its capacity to deform prior to breaking. On the other hand, sodium alginate, pectin, and linseed oil exerted little or no effect on these mechanical properties. Finally, the celluloses and wheat starch strengthened the studied earthen materials and reduced their capacity to deform prior to breaking. Therefore, it was inferred that the celluloses and wheat starch would enable these earthen materials to support a greater load prior to failure while also limiting their strain under load.

\section{Discussion}

The results of the present study revealed that the chemical nature and the structure of biopolymers exert different effects on the mechanical behavior of the earth used in the construction. It was concluded that among the biopolymers used in the present study, the cellulose fibers and wheat starch strengthened the construction earth. It would, however, be interesting to adjust the proportions of other biopolymers to investigate whether that has any enhancement effect on the mechanical behavior. The proportions selected in the present study were close to the ones used in vernacular buildings, and it was assumed that these proportions were efficient. Therefore, it would be interesting to observe the effects of other proportions on the properties of materials.

Cellulose fibers, as waste or a co-product, are quite abundant in France and are available in various forms, such as recycled paper and cardboard, paper byproducts, and agricultural or food processing byproducts, etc. Starch, which is another main component of the agro-food industry, is also abundant in France as a product or co-product [59]. 
Both cellulose and starch are glucose-based homopolymers, with either alpha or beta covalent bonding. While the beta bonds of cellulose are responsible for fiber organization, the alpha bonds in starch are responsible for maintaining the extended conformation of starch in solution. It was assumed that these differences between the two biopolymers led to different ways of strengthening the earth-based building materials. Indeed, on a macroscopic scale, i.e., in fibers and minerals, an improvement in the mechanical properties of a physical nature might be observed. On the other hand, at the molecular level, i.e., at the level of $\mathrm{OH}$ groups in the biopolymer structures and clay surfaces, a physicochemical strengthening of the earth is expected.

The cellulose fibers used in the present study were several tens of $\mu \mathrm{m}$ in length (Table 3 ). When mixed with earth, these cellulose fibers might have attained the property of distributing the applied stress along their length during compression, thereby conferring a higher load-bearing capacity to the material and then reinforcing it. In addition, the fibers could have completed the particle packing by filling the voids and reducing the number of defects in the material, which would have increased the load-bearing capacity prior to failure. Finally, the hydroxyl groups on the surface of the cellulose fibers could have formed hydrogen bonds with the clay surfaces. These bonds would have increased the adhesion among particles, thereby contributing to the mechanical reinforcement of the construction earth.

Prior to use in earth-based building materials, during the preparation of biopolymers, amylose and amylopectin were released from the starch granules at high temperatures. Amylose is linear and easily dispersed in water, while amylopectin is highly branched and forms a dense 3D network that disperses weakly in water. Therefore, it was assumed that these expanded biopolymers would create a network among the particles within the earth-based building material. As a consequence, during compression, this network would better distribute the stress in bulk. Moreover, due to the numerous hydroxyl groups present, starch would have formed hydrogen bonds with the clay surfaces. These physical and physicochemical properties would have contributed to increasing the compressive strength of the construction earth.

Each biopolymer influences the mechanical properties of the construction earth differently depending on its nature. Moreover, it was assumed that based on the nature of the construction earth, in particular the nature of the clays present, the biopolymers would exhibit a varying influence on the mechanical properties. These different action mechanisms could be tested on mortars composed of pure clays, while varying the botanical sources of the biopolymers as the variations in the size and composition of the biopolymers originate at their botanical source. For instance, one could vary the cellulose/lignin ratio or the length of the cellulose fibers. Complementary studies would allow proposing the ideal sizes and proportions for reinforcing an earth-based building material of a given composition.

Understanding these different mechanisms at different scales requires identifying the physical and physicochemical parts of the construction earth's reinforcement. On the macroscopic scale, one could measure the compressive strength of dry mortar bricks and the yield stress in the wet state [60]. This would enable determining the influence of biopolymers on the mechanics of the dry material and its workability as a building material. On the microscopic scale, one could analyze the pore arrangement of the material through mercury porosimetry in the mode of failure during compression using in-situ measurements such as X-ray microtomography. Finally, on the molecular scale, the affinity between the biopolymer and the clays could be determined by measuring their adsorption and detecting the presence of physicochemical bonds using different spectroscopic 
methods (infrared, Raman, and NMR). These aspects could be considered for future investigations to be conducted in this research area.

\section{Conclusions}

The present study aimed to evaluate the effect of using different biopolymers derived from vernacular techniques on the compressive strength of the construction soil collected from the Paris region. Different bio-based additives from known solutions were identified, and then the extracted biopolymers were used for quantitatively measuring their influence on the mechanical behavior (compressive strength, critical strain, and elastic modulus) of the construction soil.

According to the results, cellulose fibers and wheat starch were observed to increase the compressive strength of the construction earth from 3.5 MPa to 5.5 $\mathrm{MPa}$ and 4.5 $\mathrm{MPa}$, respectively. Cellulose fibers could increase the construction earth's critical strain depending on its natural source, while wheat starch exerted no impact on the critical strain of the construction earth. Moreover, the cellulose fibers did not change the elastic modulus of the construction earth, while wheat starch tended to increase it. In conclusion, cellulose and starch enable an earthen material to support greater load prior to failure.

Nonetheless, further investigations focusing on pure materials, i.e., different clays, earth binders, and biopolymers from different sources, are required to understand the mechanisms underlying these strengthening effects. The biopolymers identified as suitable for strengthening the earthen material in the present study are widely available as wastes from the paper, agricultural, and agrofood industries. Therefore, these biopolymers would contribute to the development and standardization of constructions using earth-based building materials.

\section{Acknowledgements}

The authors acknowledge Patrick Belin for the 3D printing of the plastic moulds and the compressive test implementation.

\section{Author Contributions}

Julia Tourtelot: Investigation, Methodology, Writing; Ann Bourgès: Methodology, Writing, Supervision; Emmanuel Keita: Methodology, Writing, Supervision.

\section{Funding}

This study was funded by I-SITE FUTURE from the French Research Agency (project name: Alluvium).

\section{Competing Interests}

The authors have declared that no competing interests exist.

\section{References}

1. Melià P, Ruggieri G, Sabbadini S, Dotelli G. Environmental impacts of natural and conventional building materials: A case study on earth plasters. J Clean Prod. 2014; 80: 179-186. 
2. Van Damme H, Houben H. Earth concrete. Stabilization revisited. Cem Concr Res. 2018; 114: 90102.

3. Pacheco-Torgal F, Jalali S. Earth construction: Lessons from the past for future eco-efficient construction. Constr Build Mater. 2012; 29: 512-519.

4. Qureshi MU, Chang I, Al-Sadarani K. Strength and durability characteristics of biopolymertreated desert sand. Geomech Eng. 2017; 12: 785-801.

5. Millogo Y, Aubert JE, Hamard E, Morel JC. How properties of kenaf fibers from Burkina Faso contribute to the reinforcement of earth blocks. Materials. 2015; 8: 2332-2345.

6. González-López JR, Juárez-Alvarado CA, Ayub-Francis B, Mendoza-Rangel JM. Compaction effect on the compressive strength and durability of stabilized earth blocks. Constr Build Mater. 2018; 163: 179-188.

7. Wu F, Li G, Li HN, Jia JQ. Strength and stress-strain characteristics of traditional adobe block and masonry. Mater Struct. 2013; 46: 1449-1457.

8. Silveira D, Varum H, Costa A, Martins T, Pereira H, Almeida J. Mechanical properties of adobe bricks in ancient constructions. Constr Build Mater. 2012; 28: 36-44.

9. Hamard E, Cammas C, Lemercier B, Cazacliu B, Morel JC. Micromorphological description of vernacular cob process and comparison with rammed earth. Front Archit Res. 2020; 9: 203-215.

10. Houben H, Guillaud H, Craterre. Traité de construction en terre. Marseille: Editions Parenthèses; 2006.

11. de Santé AR, Garenne-Colombes L, Plessis-Robinson L, d'Avray V. Rapport d'activité. Paris: Commission d'accès aux documents administratifs; 2018.

12. Aubert JE, Fabbri A, Morel JC, Maillard P. An earth block with a compressive strength higher than $45 \mathrm{MPa}$ ! Constr Build Mater. 2013; 47: 366-369.

13. Morel JC, Pkla A, Walker P. Compressive strength testing of compressed earth blocks. Constr Build Mater. 2007; 21: 303-309.

14. Seco A, Ramírez F, Miqueleiz L, García B. Stabilization of expansive soils for use in construction. Appl Clay Sci. 2011; 51: 348-352.

15. Walker P, Stace T. Properties of some cement stabilised compressed earth blocks and mortars. Smart Mater Struct. 1997; 30: 545-551.

16. Ouedraogo KA, Aubert JE, Tribout C, Escadeillas G. Is stabilization of earth bricks using low cement or lime contents relevant? Constr Build Mater. 2020; 236: 117578.

17. Van Damme H, Houben $\mathrm{H}$. Reply to the discussion of the paper "Earth concrete. Stabilization revisited" by ATM Marsh, A. Heath, P. Walker, BV Venkatarama Reddy, and G. Habert. Cem Concr Res. 2020; 130: 105992.

18. Marsh AT, Heath A, Walker P, Reddy BV, Habert G. Discussion of "Earth concrete. Stabilization revisited". Cem Concr Res. 2020; 130: 105991.

19. Muguda S, Booth SJ, Hughes PN, Augarde CE, Perlot C, Bruno AW, et al. Mechanical properties of biopolymer-stabilised soil-based construction materials. Geotech Lett. 2017; 7: 309-314.

20. Ardant D, Brumaud C, Habert G. Influence of additives on poured earth strength development. Mater Struct. 2020; 53: 127.

21. Millogo Y, Aubert JE, Séré AD, Fabbri A, Morel JC. Earth blocks stabilized by cow-dung. Mater Struct. 2016; 49: 4583-4594.

22. Galán-Marín C, Rivera-Gómez C, Bradley F. Ultrasonic, molecular and mechanical testing diagnostics in natural fibre reinforced, polymer-stabilized earth blocks. Int J Polym Sci. 2013; 
2013: 130582.

23. Achenza M, Fenu L. On earth stabilization with natural polymers for earth masonry construction. Mater Struct. 2006; 39: 21-27.

24. Anger R, Fontaine L. Interactions argiles/biopolymères: Patrimoine architectural en terre et stabilisants naturels d'origine animale et végétale. Villefontaine: CRAterre; 2013.

25. Bouhicha M, Aouissi F, Kenai S. Performance of composite soil reinforced with barley straw. Cem Concr Compos. 2005; 27: 617-621.

26. Vissac A, Bourgès $A$, Gandreau $D$, Anger R, Fontaine L. Argiles \& biopolymères-les stabilisants naturels pour la construction en terre. Villefontaine: CRAterre éditions; 2017. pp.86.

27. Barbieri L, Andreola F, Lancellotti I, Taurino R. Management of agricultural biomass wastes: Preliminary study on characterization and valorisation in clay matrix bricks. Waste Manage. 2013; 33: 2307-2315.

28. Pizzi A, Eaton N. The structure of cellulose by conformational analysis. 2 . The cellulose polymer chain. J Macromol Sci Phys. 1985; 22: 105-137.

29. Zugenmaier P. Crystalline Cellulose and Derivatives. Berlin: Springer Berlin Heidelberg; 2008. pp.12.

30. Brown RM. Cellulose: Molecular and Structural Biology. Dordrecht: Springer Netherlands; 2007.

31. Properties C. Alpha-, beta- and gamma-cellulose in pulp. Peachtree Corners: TAPPI; 1999. pp.59.

32. Watkins D, Nuruddin M, Hosur M, Tcherbi-Narteh A, Jeelani S. Extraction and characterization of lignin from different biomass resources. J Mater Res Technol. 2015; 4: 26-32.

33. Janshekar H, Fiechter A. Lignin: Biosynthesis, application, and biodegradation. Adv Biochem Eng Biotechnol. 1983; 27: 119-178.

34. Ardizzone S, Dioguardi FS, Mussini T, Mussini PR, Rondinini S, Vercelli B, et al. Microcrystalline cellulose powders: Structure, surface features and water sorption capability. Cellulose. 1999; 6: 57-69.

35. Jianan $C$, Shaoqiong $Y$, Jinyue R. A study on the preparation, structure, and properties of microcrystalline cellulose. J Macromol Sci A. 1996; 33: 1851-1862.

36. Thakur BR, Singh RK, Handa AK, Rao MA. Chemistry and uses of pectin-a review. Crit Rev Food Sci Nutr. 1997; 37: 47-73.

37. Seguchi MA, Higasa TA, Mori TO. Study of wheat starch structures by sonication treatment. Cereal Chem. 1994; 71: 636-639.

38. Zobel HF. Molecules to granules: A comprehensive starch review. Starke. 1988; 40: 44-50.

39. Tester RF, Karkalas J, Qi X. Starch-composition, fine structure and architecture. J Cereal Sci. 2004; 39: 151-165.

40. Pérez $\mathrm{S}$, Bertoft $\mathrm{E}$. The molecular structures of starch components and their contribution to the architecture of starch granules: A comprehensive review. Starke. 2010; 62: 389-420.

41. Swinkels JJ. Composition and properties of commercial native starches. Starke. 1985; 37: 1-5.

42. Hecht $H$, Srebnik S. Structural characterization of sodium alginate and calcium alginate. Biomacromolecules. 2016; 17: 2160-2167.

43. Atamer Z, Post AE, Schubert T, Holder A, Boom RM, Hinrichs J. Bovine $\beta$-casein: Isolation, properties and functionality. A review. Int Dairy J. 2017; 66: 115-125.

44. Chang I, Im J, Chung MK, Cho GC. Bovine casein as a new soil strengthening binder from diary wastes. Constr Build Mater. 2018; 160: 1-9. 
45. Vaia B, Smiddy MA, Kelly AL, Huppertz T. Solvent-mediated disruption of bovine casein micelles at alkaline $\mathrm{pH}$. J Agric Food Chem. 2006; 54: 8288-8293.

46. McCarthy NA, Power O, Wijayanti HB, Kelly PM, Mao L, Fenelon MA. Effects of calcium chelating agents on the solubility of milk protein concentrate. Int J Dairy Technol. 2017; 70: 415-423.

47. Power OM, Fenelon MA, O'Mahony JA, McCarthy NA. Dephosphorylation of caseins in milk protein concentrate alters their interactions with sodium hexametaphosphate. Food Chem. 2019; 271: 136-141.

48. Anema SG. The effect of hexametaphosphate addition during milk powder manufacture on the properties of reconstituted skim milk. Int Dairy J. 2015; 50: 58-65.

49. Lazzari M, Chiantore O. Drying and oxidative degradation of linseed oil. Polym Degrad Stab. 1999; 65: 303-313.

50. Sorgho B, Zerbo L, Keita I, Dembele C, Plea M, Sol V, et al. Strength and creep behavior of geomaterials for building with tannin addition. Mater Struct. 2014; 47: 937-946.

51. Keita I, Sorgho B, Dembele C, Plea M, Zerbo L, Guel B, et al. Ageing of clay and clay-tannin geomaterials for building. Constr Build Mater. 2014; 61: 114-119.

52. Banakinao S, Tiem S, Lolo K, Koutsawa Y, Bedja KS. Dataset of the use of tannin of néré (parkiabiglobosa) as a solution for the sustainability of the soil constructions in West Africa. Data Brief. 2016; 8: 474-483.

53. The International Organization for Standardization. Geotechnical investigation and testinglaboratory testing of soil-Part 12: Determination of liquid and plastic limits. Genève: The International Organization for Standardization; 2018; ISO 17892-12:2018.

54. AFNOR Store. Blocs de terre comprimée pour murs et cloisons. La Plaine Saint-Denis: AFNOR Store; 2001; XP P 13-901:2001-10.

55. Fatehi $H$, Abtahi SM, Hashemolhosseini $H$, Hejazi SM. A novel study on using protein based biopolymers in soil strengthening. Constr Build Mater. 2018; 167: 813-821.

56. Alhaik G, Dubois V, Wirquin E, Leblanc A, Aouad G. Evaluate the influence of starch on earth/hemp or flax straws mixtures properties in presence of superplasticizer. Constr Build Mater. 2018; 186: 762-772.

57. Mizuta K, Taguchi S, Sato S. Soil aggregate formation and stability induced by starch and cellulose. Soil Biol Biochem. 2015; 87: 90-96.

58. Perrot A, Rangeard D, Menasria F, Guihéneuf S. Strategies for optimizing the mechanical strengths of raw earth-based mortars. Constr Build Mater. 2018; 167: 496-504.

59. Réseau pour la sécurité et la qualité des denrées animales. Gisements et valorisations des coproduits des industries agroalimentaires. Normandie: Réseau pour la sécurité et la qualité des denrées animales. 2017. pp.121.

60. Tourtelot J, Ghattassi I, Le Roy R, Bourgès A, Keita E. Yield stress measurement for earth-based building materials: The weighted plunger test. Mater Struct. 2021; 54: 6. 


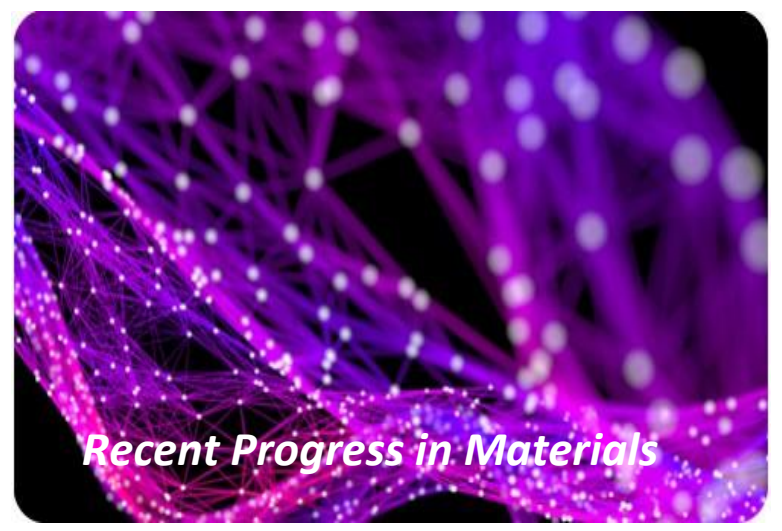

Enjoy Recent Progress in Materials by:

1. Submitting a manuscript

2. Joining in volunteer reviewer bank

3. Joining Editorial Board

4. Guest editing a special issue

For more details, please visit:

http://www.lidsen.com/journals/rpm 